\title{
11-kV Series-Connected H-Bridge Multilevel Converter for Direct Grid Connection of Renewable Energy Systems
}

\author{
Md. Rabiul Islam*, Youguang Guo*, and Jian Guo Zhu*
}

\begin{abstract}
Due to the variable nature of renewable energy resources and power demand by consumers, it is difficult to operate a power system installed with only one type of renewable energy resource. Grid-based renewable generation may be the only solution to overcome this problem. The conventional approach based on a low-voltage converter with power frequency transformer is commonly employed for grid connection of offshore renewable energy systems. Because of the heavy weight and large size of the transformer, the system can be expensive and complex in terms of installation and maintenance. In this paper, an 11-kV series connected H-bridge (SCHB) multilevel voltage source converter (VSC) is proposed to achieve a compact and light direct grid connection of renewable energy systems. This paper presents the design, simulation and analysis of a five level (5L)-SCHB and an eleven level (11L)-SCHB VSC for 11-kV grid-based renewable energy systems. The performance, cost, modulation scheme and harmonic spectra of the converter are analyzed.
\end{abstract}

Keywords : Multilevel converter, Renewable energy systems, Direct grid connection, MATLAB simulation.

\section{Introduction}

Two major global crises that mankind is facing currently, are the energy crisis and the environment/climate crisis. The dynamic growth of renewable energy directly pushes renewable energy technology into a more competitive area. Hence during the last decades, renewable energy resources have become an important part of the worldwide concern with clean power generation. Scientists and researchers have been trying to discover effective technologies for renewable generation systems. Many countries have set targets for renewable energy use to meet the increasing power demand and also to reduce the greenhouse effect. The target share of total energy from renewables of some countries is shown in Table 1 [1].

Solar and wind are main renewable energy sources for future electricity supply. The global renewable energy achievement rate from these two sources is also high. Solar photovoltaic (PV) technology is used to generate electricity in well over 100 countries and continues to be the fastest growing renewable energy source in the world. Between 2004 and 2009, grid-connected PV capacity increased at an

\footnotetext{
* School of Electrical, Mechanical and Mechatronic Systems, Faculty of Engineering and Information Technology, University of Technology Sydney (UTS), 15 Broadway, Ultimo, NSW 2007, Australia. (Md.Islam@uts.edu.au)

Received 10 July 2011; Accepted 20 February 2012
}

annual average rate of $60 \%$ and over this five year period, annual growth rate for cumulative wind power capacity averaged $27 \%$. The installed capacity in 2009 was equivalent to nearly a quarter of total global installations and cumulative capacity has doubled in less than three years. The global installed wind power capacity is shown in Fig. 1 [2].

Table 1. Renewable Energy Targets

\begin{tabular}{|c|c|c|}
\hline Country & Year & Renewable (\%) \\
\hline Australia & 2020 & 20 \\
\hline Denmark & 2025 & 50 \\
\hline Finland & 2020 & 38 \\
\hline France & 2020 & 23 \\
\hline Germany & 2020 & 18 \\
\hline UK & 2020 & 15 \\
\hline US & 2025 & 25 \\
\hline Sweden & 2020 & 49 \\
\hline Austria & 2020 & 34 \\
\hline
\end{tabular}

The availability of renewable energy sources is strongly dependent on daily and seasonal patterns and the power demand by consumers could have a very different characteristic. So it is difficult to operate a power system installed with only one type of renewable energy resource. Grid-based renewable generation may be the only solution to overcome this problem but, due to the variable nature of renewable energy sources, output voltage and frequency 
adjustments make connecting these systems to power grids challenging. Different power electronic converters have been developed using conventional topologies to fulfill the requirements of renewable generations [3]. All of them contain magnetic components, e.g. transformers, which not only increase the size, weight and losses but also increase the cost and complexity of the system operation. An isolation transformer represents $30 \%$ to $50 \%$ of a total system size and $50 \%$ to $70 \%$ of the system's weight [4]. An 1-MVA transformer, for example, can generate up to 6800 $\mathrm{Btu} / \mathrm{h}$ of heat, which requires a significant amount of cooling power. These penalties are critical in offshore renewable energy applications, where the cost of installation and regular maintenance is extremely high. Thus, reducing the transformer size and weight can save large amounts of installation, running and maintenance costs.

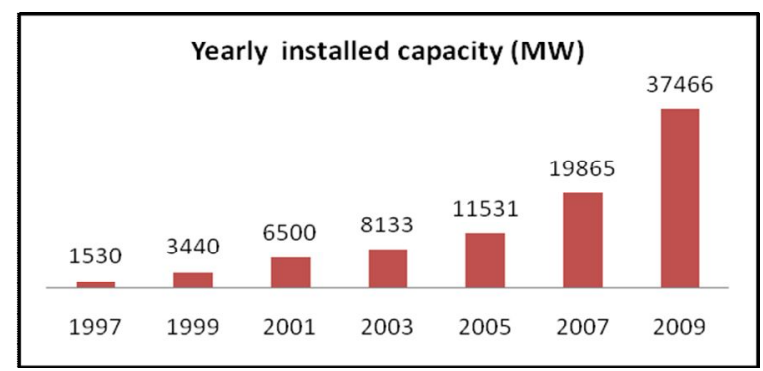

(a)

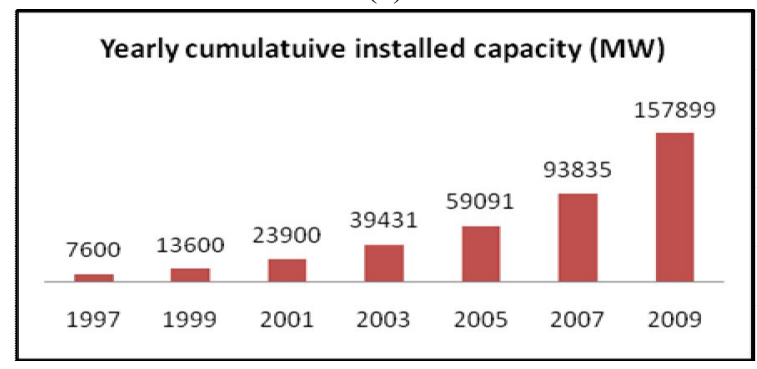

(b)

Fig. 1. Global installed wind power capacity: (a) Annual, (b) Cumulative

In order to stabilize the system operation, harmonic control is also important. To mitigate this harmonic effect it is essential to use a filter coil, which also increases the system complexity and cost. Although the continuous race to develop higher-voltage and higher-current power semiconductors to drive high-power systems goes on, it is still hard to connect a single-power semiconductor switch directly to a high-voltage grid (e.g. $11 \mathrm{kV})$ [5]. The seriesparallel connection of lower rated semiconductors could be the cost effective solution for high voltage applications.

A new family of multilevel converters has emerged as a solution for working with medium/high-voltage applications. There are three main popular topologies in multilevel converters: neutral point clamped (NPC), flying capacitor (FC), and SCHB [6], [7]. In recent years, they have become more attractive due to some special features, like better harmonic performance, drawing input current with very low distortion, lower voltage stress in power semiconductor switches and lower switching frequency capability, as compared to other topologies.

Output voltage waveforms of the converter could be improved by increasing the number of levels of the converter, which may reduce the size of the input and output filter requirements. The percentage of total harmonic distortion (THD) of different-level inverters is shown in Table 2. The cascaded/multilevel connection of low-ratedvoltage devices could be the possible cost-effective solution of high-voltage high-power applications [8]. As a result, it is now required and not difficult to develop, an $11-\mathrm{kV}$ multilevel VSC, which may be able to connect a renewable generation system to the grid without introducing a power transformer.

Table 2. Harmonics comparison of the inverters

\begin{tabular}{|c|c|c|c|c|}
\hline Level & $2 \mathrm{~L}$ & $3 \mathrm{~L}$ & $5 \mathrm{~L}$ & $11 \mathrm{~L}$ \\
\hline THD (\%) & 107 & 42 & 17.26 & 7.07 \\
\hline
\end{tabular}

Among these three multilevel converter topologies the NPC and FC topologies have the disadvantages that the number of components scales quadratically and capacitor voltage balancing problems become intractable with respect to the number of levels. In these regards the SCHB topology is suitable for high-voltage as well as high-level converters. However, many publications have addressed the limitation of the SCHB converter, which requires multipleisolated balanced DC supplies and, therefore, its application is not straightforward [9].

By increasing the operating frequency, much research has been done to reduce the size and weight of the power transformer [10]. Multi-windings high-frequency transformers can be used to generate the isolated balanced multiple DC supplies for the SCHB converter from a single low -voltage power source.

This paper proposes a high-frequency transformer-linkbased SCHB multilevel converter for direct grid connection of renewable energy systems. The converter is designed, the performance is simulated and, also, the cost of power semiconductors and passive components is calculated.

\section{Design and Specifications}

Fig. 2 shows the basic block diagram of the proposed converter. The output of a wind turbine is connected to AC 
to DC converter which provides DC voltage to a highfrequency inverter. The output of the high-frequency inverter is used to energize the primary of the multiwinding high-frequency transformer. The required isolated balanced multiple DC supplies for the H-bridge cells are obtained through AC-to-DC converters at the secondary side. The SCHB multilevel converter is directly connected to the grid through a small size filter. The operating conditions and basic converter data are shown in Table 3.

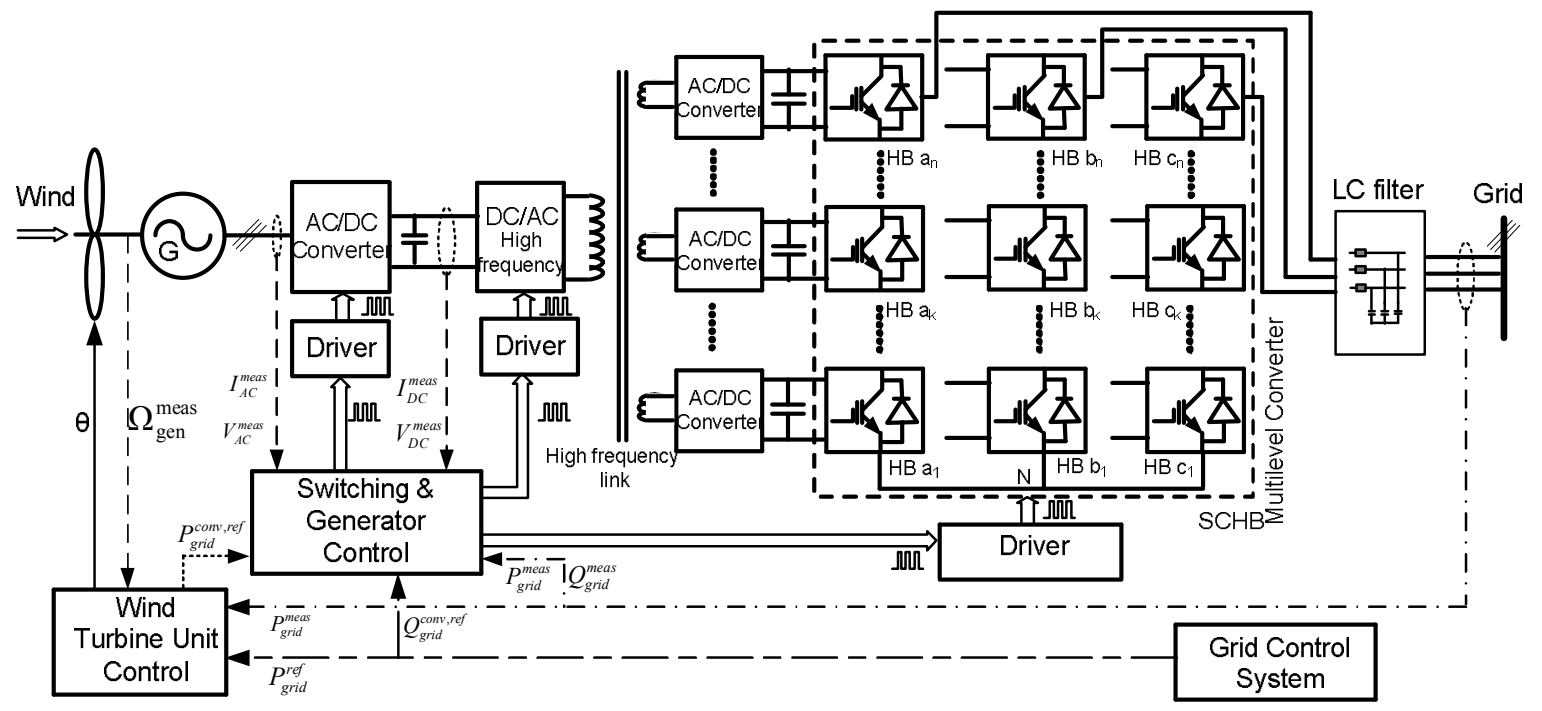

Fig. 2. Basic block diagram of the proposed system for direct grid connection.

\subsection{Multilevel Converter Section}

The 5L/11L-SCHB multilevel VSC topology is used to implement the high-voltage converter section of the proposed systems. The overall system performance highly depends on the performance of this section. Therefore, it is required to give careful attention to the selection of the converter topology. The semiconductor utilization is a very important criterion for the evaluation of high-voltage topologies due to the high cost of semiconductors. The minimum DC-link voltage $V_{d c(\text { min })}$ necessary to achieve an output line-to-line voltage $V_{l l(r m s)}$ of $11-\mathrm{kV}$ can be calculated from

$$
V_{d c(\min )}=\frac{\sqrt{2} \times V_{l l(r m s)}}{(L-1)}
$$

Table 3. Basic converter data

\begin{tabular}{|l|c|c|}
\hline \multicolumn{1}{|c|}{ Technical Data } & $5 \mathrm{~L}$ & $11 \mathrm{~L}$ \\
\hline Converter line-to-line voltage $\left(V_{l(\text { (rms })}\right)$ & $11 \mathrm{kV}$ & $11 \mathrm{kV}$ \\
\hline Minimum DC-link voltage $\left(V_{d c(\text { min })}\right)$ & $3889 \mathrm{~V}$ & $1556 \mathrm{~V}$ \\
\hline Nominal DC-link voltage $\left(V_{d c(\text { nom })}\right)$ & $4045 \mathrm{~V}$ & $1618 \mathrm{~V}$ \\
\hline Phase current $\left(I_{p(r m s)}\right)$ & $250 \mathrm{~A}$ & $250 \mathrm{~A}$ \\
\hline Converter output apparent power $\left(S_{c}\right)$ & $4.76 \mathrm{MVA}$ & $4.76 \mathrm{MVA}$ \\
\hline Converter carrier frequency $\left(f_{c}\right)$ & $1-2 \mathrm{kHz}$ & $1-2 \mathrm{kHz}$ \\
\hline Output frequency $\left(f_{o}\right)$ & $50 \mathrm{~Hz}$ & $50 \mathrm{~Hz}$ \\
\hline
\end{tabular}

To determine the nominal DC-link voltage of the converter, a voltage reserve of $4 \%$ is assumed [11], i.e.

$$
V_{d c(\text { nom })}=1.04 \times V_{d c, \min }
$$

The converter output apparent power can be calculated us ing

$$
\begin{gathered}
S_{c}=\sqrt{3} \times V_{l l(r m s)} \times I_{p(\mathrm{rms})} \\
=\sqrt{3} \times 11 \mathrm{kV} \times 250 \mathrm{~A}=4.76 \mathrm{MVA}
\end{gathered}
$$

The DC-link voltage needs to be considered when selecting IGBTs and diodes in order to select the proper voltage ratings; and cosmic ray effects assessment may also be necessary. In addition to the output capacity and voltage ratings of the converter, the availability of IGBT and diode modules in the market needs to be considered in the design process. Two $4.5 \mathrm{kV}$ series-connected IGBTs are assumed as a single switch for the $5 \mathrm{~L}$ converter topologies. Table 4 summarizes the design choices of the power semiconductor devices for the multilevel converter section, with a carrier frequency of 1-2 kHz. To allow for a converter output phase current of $250 \mathrm{~A}$, a $400 \mathrm{~A} / 360 \mathrm{~A}(5 \mathrm{~L} / 11 \mathrm{~L})$ current rating is chosen for the power semiconductor devices.

\subsection{Rectifier Section}

Generation side power flow control can be implemented through the turbine side AC-to-DC converter section. A diode bridge rectifier may be an alternative choice to 
simplify the circuit and reduce the system cost. The rms output voltage of a common wind generator is $690 \mathrm{~V}$, and then DC output voltage at the rectifier terminal can be calculated as

$$
V_{d c(\text { recti })}=1.654 \times V_{m}=932 \mathrm{~V}
$$

where $\mathrm{V}_{\mathrm{m}}(563 \mathrm{~V})$ is the peak value of the phase voltage. The peak inverse voltage (PIV) can be calculated as

$$
P I V=\sqrt{3} \times V_{m}=976 \mathrm{~V}
$$

The ratings of the power components are shown in Table 5.

Single-phase diode bridge rectifiers with fast recovery diodes are considered to convert high-frequency alternating quantities to DC quantities. Each H-bridge cell is associated with a separate rectifier.

Table 4. IGBT's ratings

\begin{tabular}{|l|c|c|}
\hline & $5 \mathrm{~L}-\mathrm{SCHB}$ & $11 \mathrm{~L}-\mathrm{SCHB}$ \\
\hline Nominal DC voltage & $4045 \mathrm{~V}$ & $1618 \mathrm{~V}$ \\
\hline IGBT's voltage rating & $2 \times 4.5 \mathrm{kV}$ & $3.3 \mathrm{kV}$ \\
\hline $\begin{array}{l}\text { Commutation voltage of respective } \\
\text { commutation cells, } V_{\text {com }}\end{array}$ & $2022 \mathrm{~V}$ & $1618 \mathrm{~V}$ \\
\hline $\begin{array}{l}\text { Device commutation voltage for a } \\
\text { device reliability of 100FIT due to } \\
\text { cosmic radiation, } V_{\text {com@100FIT }}\end{array}$ & $2 \times 2250 \mathrm{~V}$ & $1800 \mathrm{~V}$ \\
\hline $\begin{array}{l}\text { Device voltage utilization factor, } \\
V_{\text {com }} V_{\text {com@100FIT }}\end{array}$ & 0.90 & 0.90 \\
\hline IGBT's current rating & $400 \mathrm{~A}$ & $360 \mathrm{~A}$ \\
\hline
\end{tabular}

Table 5. Power components in the rectifier

\begin{tabular}{|c|c|c|}
\hline & $5 \mathrm{~L}-\mathrm{SCHB}$ & $11 \mathrm{~L}-\mathrm{SCHB}$ \\
\hline Unit voltage (rms) & $690 \mathrm{~V}$ & $690 \mathrm{~V}$ \\
\hline Average output voltage & $932 \mathrm{~V}$ & $932 \mathrm{~V}$ \\
\hline PIV of the diodes & $976 \mathrm{~V}$ & $976 \mathrm{~V}$ \\
\hline
\end{tabular}

\subsection{High-Frequency Link Transformer}

A material which can be easily magnetized and demagnetized, referred to as soft magnetic material, is generally used for high-frequency transformers. With the advent of new power semiconductor devices, different high-magnetic-saturation and low-power-loss soft magnetic materials have been conceived to reduce the weight and volume of conventional power transformers. Ferrite material has gained popularity due to its price and availability. But, it has very low flux density (between 0.3 and $0.5 \mathrm{~T}$ ) which makes a transformer bulky especially for high-voltage and high-frequency systems. Silicon steel is one of the soft magnetic materials that have high saturation flux density of around $1.5 \mathrm{~T}$ and good permeability.
Compared with other soft magnetic materials, like amorphous and nanocrystalline, its specific core loss is very high. The amorphous alloy based soft magnetic material is called Metglas. Metglas has not only high permeability but also high saturation flux density of $1.56 \mathrm{~T}$. The specific core loss of Metglas amorphous alloy is much lower than that of silicon steel but higher than that of nanocrystalline. The core loss of Metglas amorphous alloy is shown in Figs. 3-4.

Nanocrystalline has high saturation flux density of around $1 \mathrm{~T}$ and extremely low losses. Although it has very low core losses, the insulation issue and cost makes it unpopular, especially for toroidal cores. However, special consideration must be given to reducing the losses, since the behavior of a transformer can significantly change as frequency increases due to redistribution of the magnetic field and the current density within the conductors. Considering the flux density, loss and availability, a Metglas 2506SA1 soft magnetic material with saturation flux density of $1.56 \mathrm{~T}$ and specific loss of $0.6 \mathrm{~kW} / \mathrm{kg}$ is chosen as the core material.

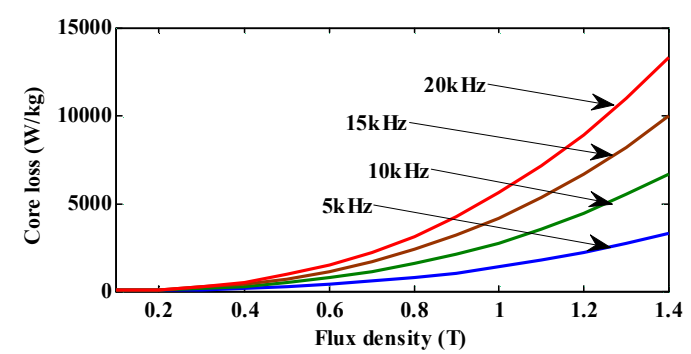

Fig. 3. Core loss versus flux density of Metglas amorphous alloy

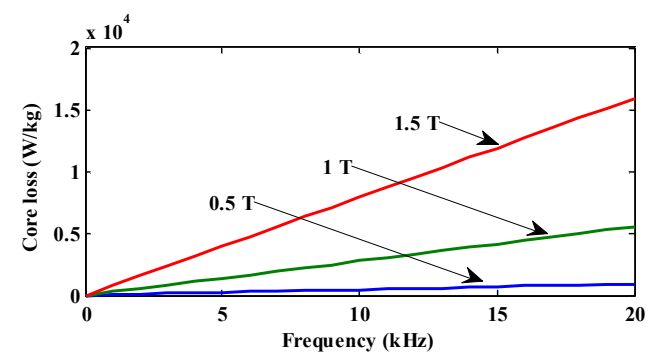

Fig. 4. Core loss versus frequency of Metglas amorphous alloy

Moreover, the transformer operates with a square-wave voltage, so it needs a different design, since triangular flux is required to generate a square wave voltage. Fig. 5 shows the waveforms of the voltage and flux. If $f$ is the excitation frequency, $V_{r m s}$ is the excitation voltage, $A$ is the core area, and $B_{\max }$ is the maximum flux density, then the minimum number of turns $N$ in the primary winding, can be expressed as in equation (6). 


$$
N=\frac{V_{r m s}}{4 \cdot f \cdot B_{\max } \cdot A}
$$

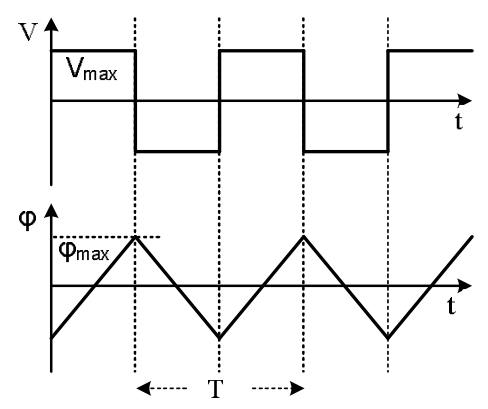

Fig. 5. Voltage and flux in a square-wave transformer

\subsection{Modulation Scheme}

Different modulation schemes have been adapted or developed depending on the application and the converter topology, and each has its unique advantages and disadvantages. The most common modulation method in industry is carrier-based sine triangle modulation. The phase-shifted-sine pulse-width modulation (PS-SPWM) method is especially useful for series-cascaded H-bridge (SCHB) converters [12]. In this paper a PS-SPWM scheme is used to analyze the converter performance. Fig. 6 shows the PS-SPWM scheme for a 5L-SCHB converter where switching pulse generating signals of two successive cells are shown separately in (b) and in (c). The modulation scheme for an 11L converter is shown in Fig. 7.

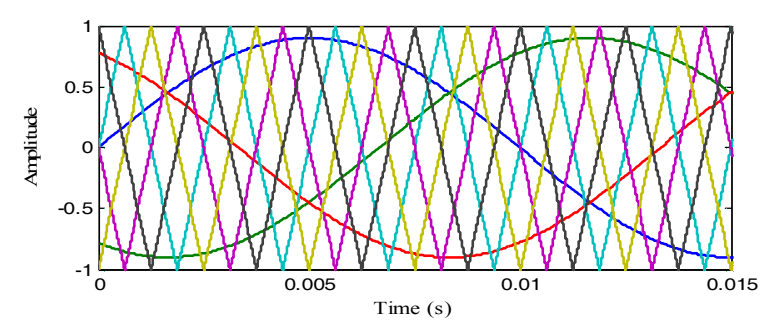

(a)

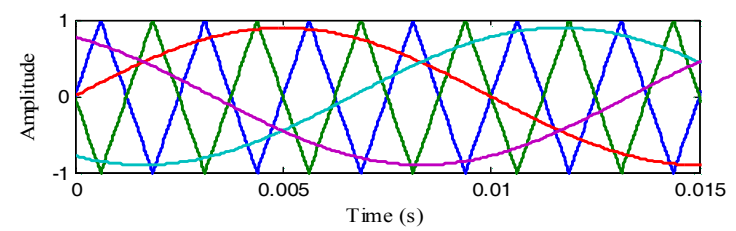

(b)

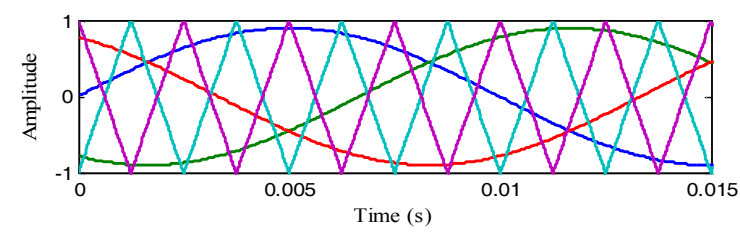

(c)

Fig. 6. Modulation schemes for $5 \mathrm{~L}-\mathrm{SCHB}$ VSC:

(a) All cells, (b) and (c) Two successive cells.

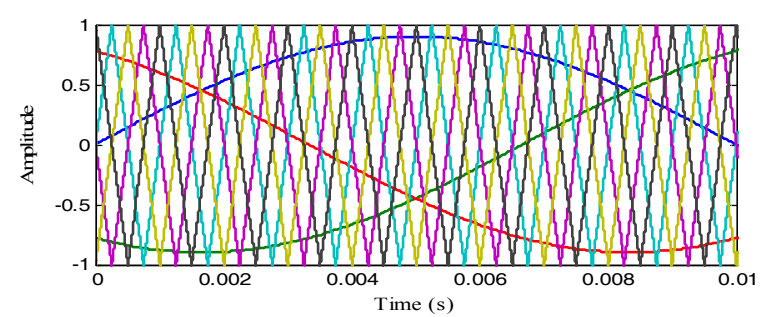

(a)

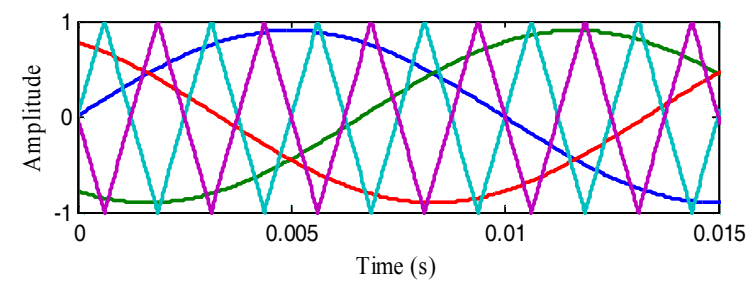

(b)

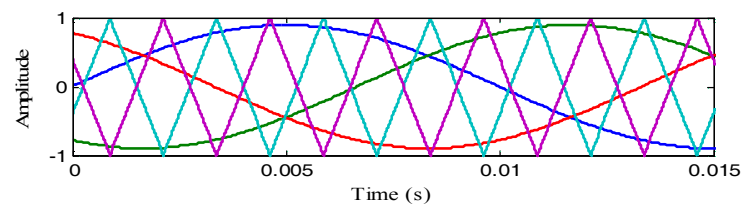

(c)

Fig. 7. Modulation schemes for 11L-SCHB VSC:

(a)All cells, (b) and (c) Two successive cells.

\section{Simulation Results}

The performance is analyzed and compared in Matlab/Simulink environment. To generate switching pulses, a PS-SPWM scheme is used for the SCHB multilevel converter topology with a carrier frequency of 1$2 \mathrm{kHz}$ and modulation index of $0.8-0.9$. The $5 \mathrm{~L}$ converter output line voltage at the inverter terminal is shown in Fig. 8 and the line voltage at the load terminal is shown in Fig. 9. Fig. 10 shows the line current of the $5 \mathrm{~L}$ converter. The respective harmonic spectra are shown in Fig. 11 to Fig. 13. The 11L converter output line voltage at the inverter terminal and at the load terminal, and the line current, are shown in Fig. 14 to Fig. 16, respectively. Also, their harmonic spectra are shown in Fig. 17 to Fig. 19, respectively.

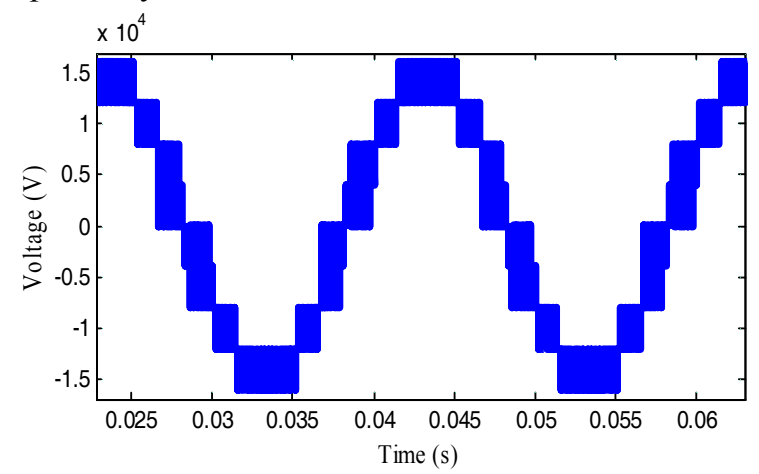

Fig. 8. Line voltage of 5L-SCHB VSC at inverter terminal. 


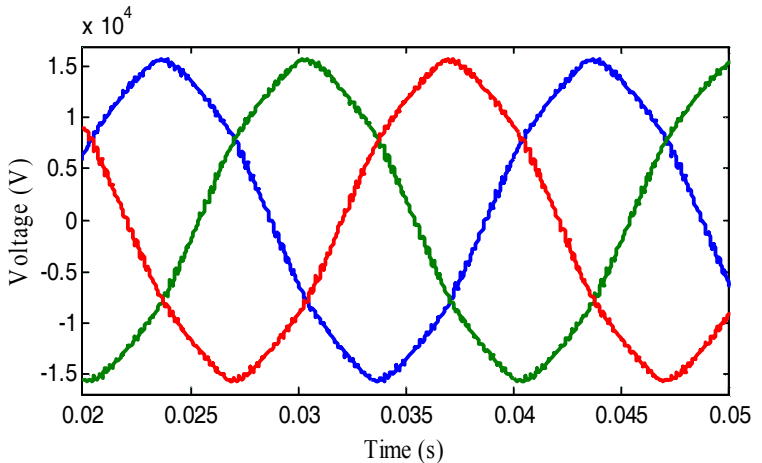

Fig. 9. Line voltage of 5L-SCHB VSC at load terminal.

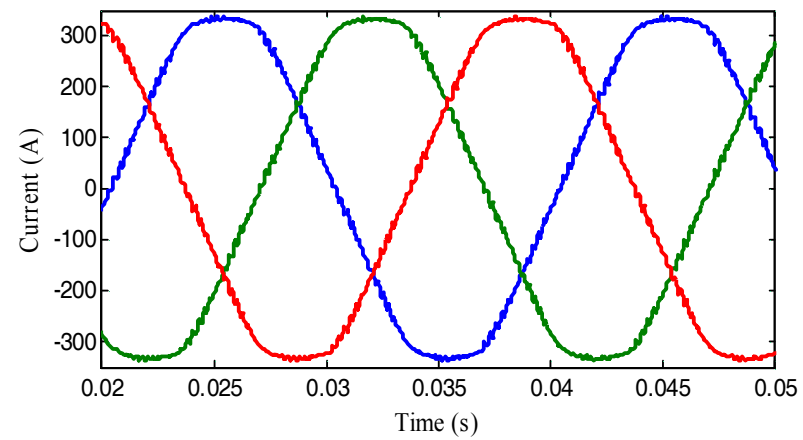

Fig. 10. Line current of 5L-SCHB VSC.

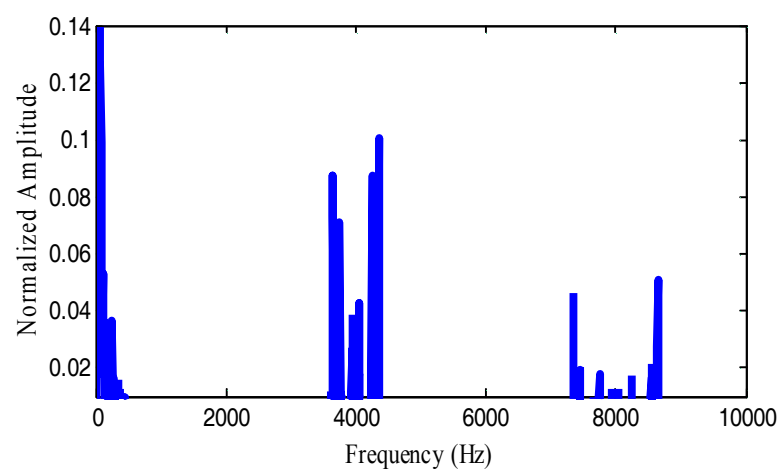

Fig. 11. Line voltage harmonic spectrum of 5L-SCHB VSC at inverter.

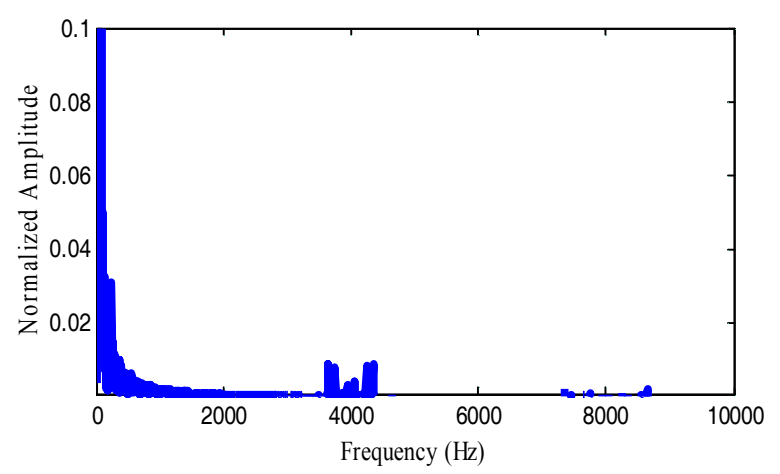

Fig. 12. Line voltage harmonic spectrum of 5L-SCHB VSC at load.

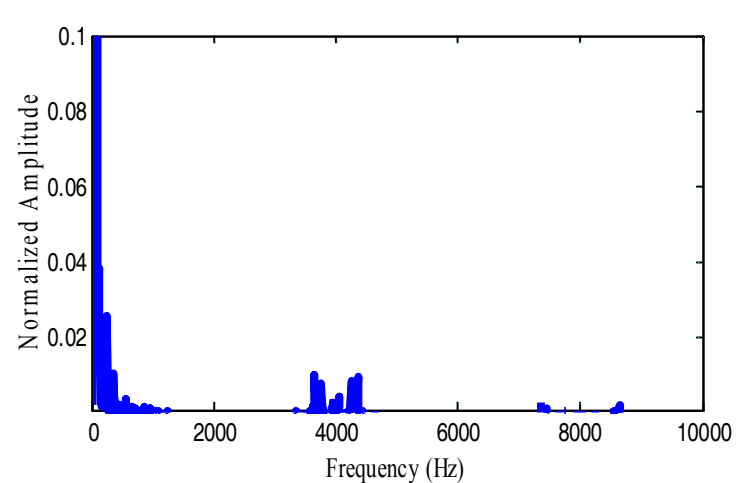

Fig. 13. Line current harmonic spectrum of $5 \mathrm{~L}-\mathrm{SCHB}$ VSC.

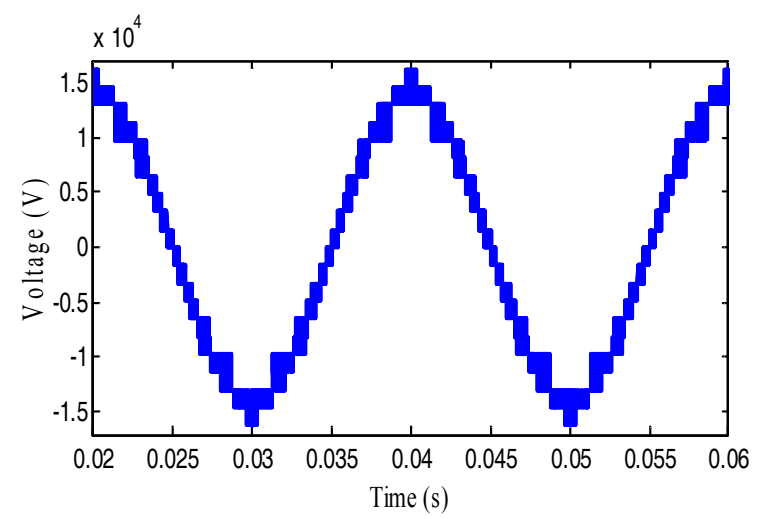

Fig. 14. Line voltage of 11L-SCHB VSC at inverter terminal.

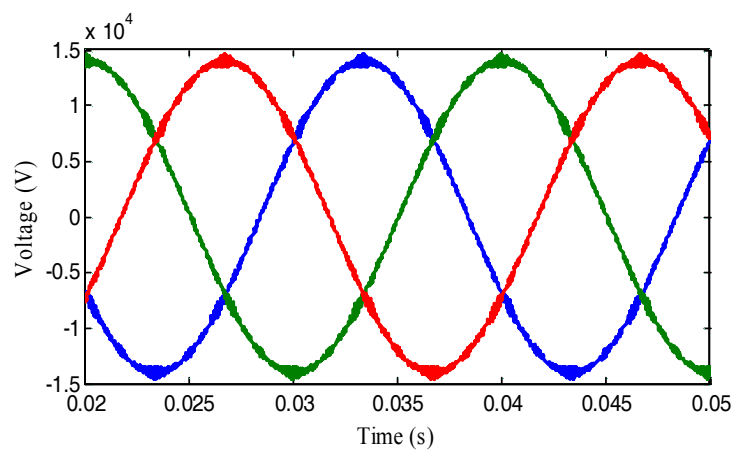

Fig. 15. Line voltage of 11L-SCHB VSC at load.

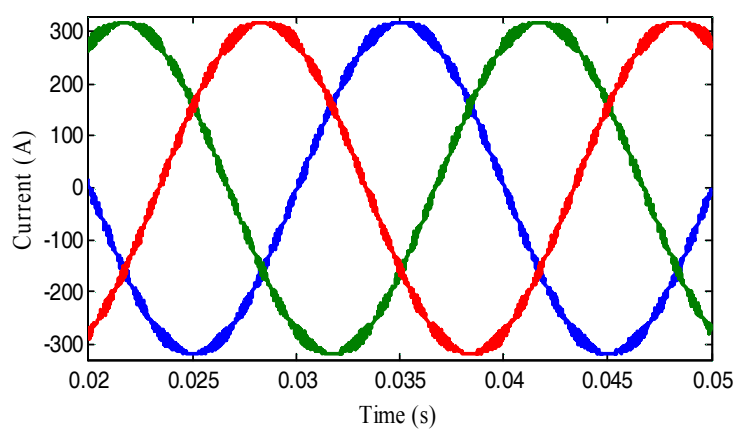

Fig. 16. Line current of 11L-SCHB VSC. 


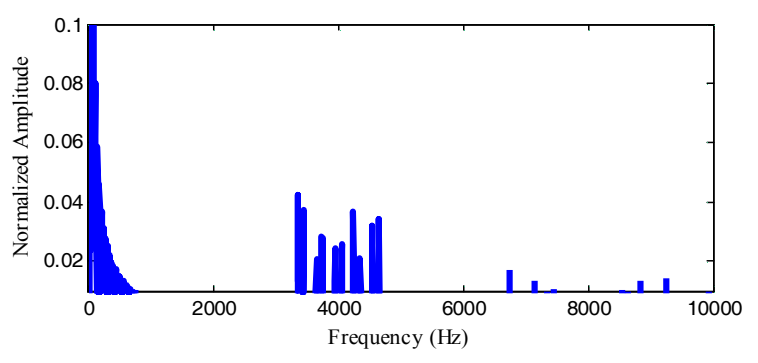

Fig. 17. Line voltage harmonic spectrum of $11 \mathrm{~L}-\mathrm{SCHB}$ VSC at inverter.

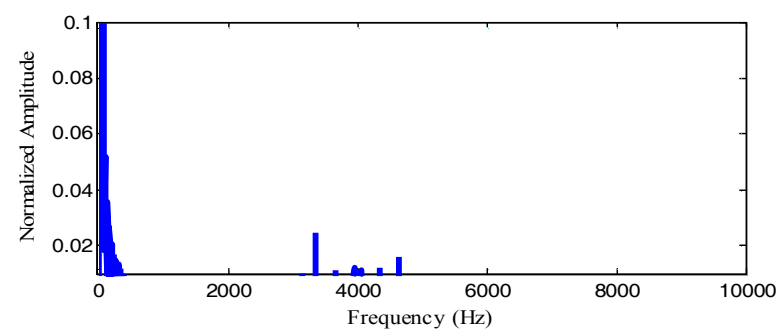

Fig. 18. Line voltage harmonic spectrum of 11L-SCHB VSC at load.

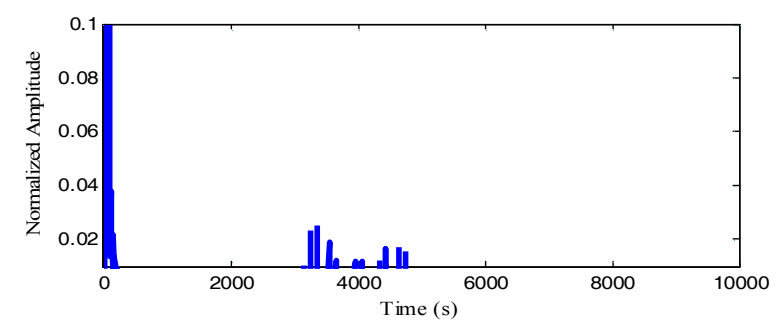

Fig. 19. Line current harmonic spectrum of $11 \mathrm{~L}-\mathrm{SCHB}$ VSC.

\section{Performance and Cost}

The harmonic content decreases rapidly with increasing number of levels. The size of the LC filter is also reduced. Table 6 shows the THD for both the multilevel converter output voltage and current. This means that by increasing the number of levels of the converter, it is possible to keep the output voltage total harmonic distortion to less than, or equal to $5 \%$ (which is required by IEEE standard 5191999). In this way, the SCHB converter can be made more economical than the others (NPC/FC) because it is easy to increase the number of levels.

LC filters are used to improve the output harmonic performance of both converters, which is less than $5 \%$. Among these two converters, the 5L-SCHB converter system requires a relatively larger size filter than the $11 \mathrm{~L}$ SCHB system. It is also observed that, the harmonic performance of the SCHB topology having a level number of 19 is good enough (less than 5\% harmonic distortion) to connect the converter to the local grid directly, without using a filter.

Table 6. Converter performance

\begin{tabular}{|l|c|c|}
\hline & 5L-SCHB & 11L-SCHB \\
\hline $\begin{array}{l}\text { THD (\%) in line voltage at inverter } \\
\text { terminal }\end{array}$ & 20 & 9 \\
\hline THD (\%) in line current & 3.1 & 2.5 \\
\hline
\end{tabular}

There are no blocking diodes or clamping capacitors in the SCHB multilevel converter topology. The number of components of this topology scales linearly with the number of levels. Hence, the overall number of components is much lower than that of other topologies. The numbers of power components for each converter topology is listed in Table 7. The number of components and the corresponding cost of turbine-side rectifier, high-frequency inverter and high-frequency transformer are the same in both cases, 5L and $11 \mathrm{~L}$. The individual modules are similar and totally modular in construction, which makes the system easy to implement for any number of levels. Hence, SCHB converter is a low-cost high-performance converter and it is suitable for the connection of an $11-\mathrm{kV}$ system directly to the grid. The price data quoted for the semiconductor devices and capacitors were collected from the Galco Industrial Electronics and Farnell catalogues [13], [14] where devices were chosen from the same family in order to meet the requirements. The filter inductor and highfrequency transformer are custom designs. Therefore, their costs depend on the design. The material costs of the inductor can be estimated. The IGBTs chosen have integrated freewheel diodes and, hence, these diodes do not appear in the costing. The current rating of most devices is selected on the basis of simulation results. Table 8 shows the estimated cost of the two converter systems. The number of semiconductor devices increases with the number of levels but the change of cost is small because the price of the low-rated-voltage devices is relatively very low. Because of the lower voltage and current requirements, the total semiconductor cost of the $11 \mathrm{~L}-\mathrm{SCHB}$ converter is lower than that of 5L-SCHB converter system.

Table 7. Number of power components

\begin{tabular}{|c|c|c|c|}
\hline & & 5L-SCHB & 11L-SCHB \\
\hline \multirow{2}{*}{$\begin{array}{l}\text { SCHB } \\
\text { section }\end{array}$} & Number of IGBTs & $24+24$ & 60 \\
\hline & Sub total & 48 & 60 \\
\hline \multirow{3}{*}{$\begin{array}{l}\text { High- } \\
\text { frequency } \\
\text { rectifier } \\
\text { section }\end{array}$} & Number of diodes & 24 & 60 \\
\hline & Number of filter capacitors & 6 & 15 \\
\hline & Sub total & 30 & 75 \\
\hline $\begin{array}{l}\text { All } \\
\text { sections }\end{array}$ & Total component count & 78 & 135 \\
\hline
\end{tabular}




\section{Conclusions}

The number of components of the SCHB converter scales linearly with the number of levels. Due to the modular nature of the construction, it is easy to attain high level numbers. A high number of levels means that the output filter sizes can be minimized, and it allows for the possibility of direct connection to the medium- or highvoltage network. This direct connection leads to the elimination of heavy, bulky, lossy and costly transformers from the system. A high-frequency link transformer is possible solution to meet the requirement of isolated balanced DC supplies for the SCHB multilevel converter. According to converter cost, complexity and performance, it is concluded that the SCHB multilevel converter with high-frequency link is the most feasible converter for direct grid connection of renewable energy systems.

Table 8. Estimated cost for power components

\begin{tabular}{|c|c|c|c|}
\hline & & 5L-SCHB & 11L-SCHB \\
\hline \multirow{2}{*}{$\begin{array}{l}\text { Cost of } \\
\text { semicondu } \\
\text { ctors } \\
\text { (AU\$) }\end{array}$} & Costs of IGBTs (inverter) & 82,027 & 82,159 \\
\hline & $\begin{array}{l}\text { Total cost of } \\
\text { semiconductors }\end{array}$ & 82,027 & 82,159 \\
\hline \multirow{3}{*}{$\begin{array}{l}\text { Costs of } \\
\text { passive } \\
\text { component } \\
\text { s (AU\$) }\end{array}$} & Material costs of LC filter & 20,500 & 12,300 \\
\hline & Costs of DC capacitors & 9,288 & 12,480 \\
\hline & $\begin{array}{l}\text { Total costs of passive } \\
\text { components }\end{array}$ & 29,788 & 24,780 \\
\hline All & Total costs (AU\$) & 111,815 & 106,939 \\
\hline
\end{tabular}

\section{References}

[1] Renewable Energy Policy Network. (June 2011). Renewables 2010 Global Status Report. [Online]. Available at: http://www.ren21.net/Portals/97/documents/GSR/REN21_G SR_2010_full_revised\%20Sept 2010.pdf

[2] Global Wind Energy Council. (June 2011). Global Wind Report, Annual Market Update 2010. [Online]. Available at: $\mathrm{http}: / /$ www.gwec.net/fileadmin/images/Publications/GWEC annual_market_update_2010_-_2nd_edition_April_2011.pdf

[3] S. Kouro, M. Malinowski, K. Gopakumar, et al., "Recent Advances and Industrial Applications of Multilevel Converters", IEEE Transactions on Industrial Electronics, vol. 57, no. 8, pp. 2553-2580, Aug., 2010.

[4] H. Abu-Rub, J. Holtz, J. Rodriguez and G. Baoming, "Medium Voltage Multilevel Converters-State of the Art, Challenges, and Requirements in Industrial Applications," IEEE Transactions on Industrial Electronics, vol. 57, no. 8, pp. 2581-2596, Aug., 2010.

[5] J. Rodriguez, L. G. Franquelo, J. I. Leon, et al, "Multilevel Converters: an Enabling Technology for High-Power Applications", Proceedings of IEEE, vol. 97, no. 11, pp. 1786-1817, Nov., 2009.

[6] J. S. Lai and F. Z. Peng, "Multilevel Converters-a New Breed of Power Converters", IEEE Transactions on Industry Applications, vol. 32, no. 3, pp. 509-517, May, 1996.
[7] A. Nabae, et al., "A New Neutral-Point-Clamped PWM Inverter", IEEE Transactions on Industry Applications, vol. 17, pp. 518-523, Sep., 1981.

[8] M. R. Islam, Y. Guo and J. G. Zhu, "H-Bridge Multilevel Voltage Source Converter for Direct Grid Connection of Renewable Energy Systems", Proceedings of 2011 IEEE PES Innovative Smart Grid Technology Conference, ISGT Asia 2011, 13-16 Nov., 2011, Perth, Australia.

[9] P. W. Hammond, "A New Approach to Enhance Power Quality for Medium Voltage AC Drives", IEEE Transactions on Industry Applications, vol. 33, pp. 202-208, Jan., 1997.

[10] M. Sabahi, A. Y. Goharrzi, S. H. Hosseini, M. B. B. Sharifian and G. B. Gharehpetian, "Flexible Power Electronic Transformer", IEEE Transactions on Power Electronics, vol. 25, no. 8, pp. 2159-2169, Aug., 2010.

[11] D. Krug, S. Bernet, S. S. Fazel, et al., "Comparison of $2.3 \mathrm{kV}$ Medium Voltage Multilevel Converters for Industrial Medium Voltage Drives", IEEE Transactions on Industrial Electronics, vol. 54, no. 6, pp. 2979-2992, Dec., 2007.

[12] J. Rodriguez, J. S. Lai and F. Z. Peng, "Multilevel Inverters: a Survey of Topologies, Controls, and Applications", IEEE Transactions on Industrial Electronics, vol. 49, no. 4, pp. 724- 738, Aug., 2002.

[13] Galco Industrial Electronics. (January 2011). Semiconductors. [Online]. Available at: http://www. galco.com/scripts/cgiip.exe/wa/wcat/catalog. htm

[14] Farnell/Element14. (December 2010). Semiconductor Modules and Passive Components. [Online]. Available at: http://au.element14.com

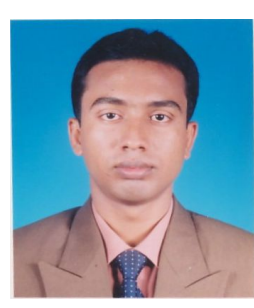

Md. Rabiul Islam was born in Rangpur, Bangladesh in 1980. He received the B.Sc. and M.Sc. degree from Rajshahi University of Engineering and Technology (RUET), Bangladesh in 2003 and 2009 respectively, both in Electrical and Electronic Engineering. From 2005 to 2008, he lectured in the Department of Electrical and Electronic Engineering, RUET. In June 2008 he joined as an Assistant Professor in the same department. $\mathrm{He}$ is currently working toward the Ph.D. degree with School of Electrical, Mechanical and Mechatronic Systems, University of Technology Sydney (UTS), Australia. His research interests are in the fields of power electronic multilevel converters, renewable energy systems and smart grid.

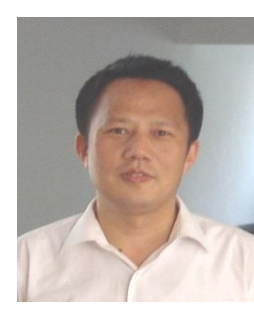

Youguang Guo was born in Hubei, China in 1965. He received the B.E. degree from Huazhong University of Science and Technology (HUST), China in 1985, the M.E. degree from Zhejiang University, China in 1988, and the $\mathrm{PhD}$ degree from University of Technology, Sydney (UTS), Australia in 2004, all in Electrical Engineering. From 1988 to 1998, he lectured in 
the Department of Electric Power Engineering, HUST. From March 1998 to July 2008, he worked as visiting research fellow, $\mathrm{PhD}$ candidate, postdoctoral fellow and research fellow in the Center for Electrical Machines and Power Electronics, Faculty of Engineering, UTS. He is currently a senior lecturer at the School of Electrical, Mechanical and Mechatronic Systems, UTS. His research fields include measurement and modeling of magnetic properties of magnetic materials, numerical analysis of electromagnetic fields, electrical machine design and optimization, power electronic drives and control.

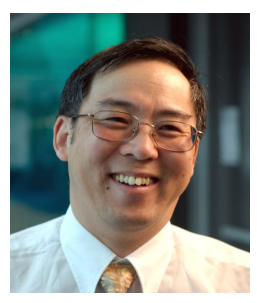

Jian Guo Zhu received his BE in 1982 from Jiangsu Institute of Technology, China, ME in 1987 from Shanghai University of Technology, China, and $\mathrm{Ph} . \mathrm{D}$ in 1995 from University of Technology, Sydney (UTS), Australia. $\mathrm{He}$ currently holds the positions of Professor of Electrical Engineering and Head for School of Electrical, Mechanical and Mechatronic Systems at UTS, Australia. His research interests include electromagnetics, magnetic properties of materials, electrical machines and drives, power electronics, and renewable energy systems. 